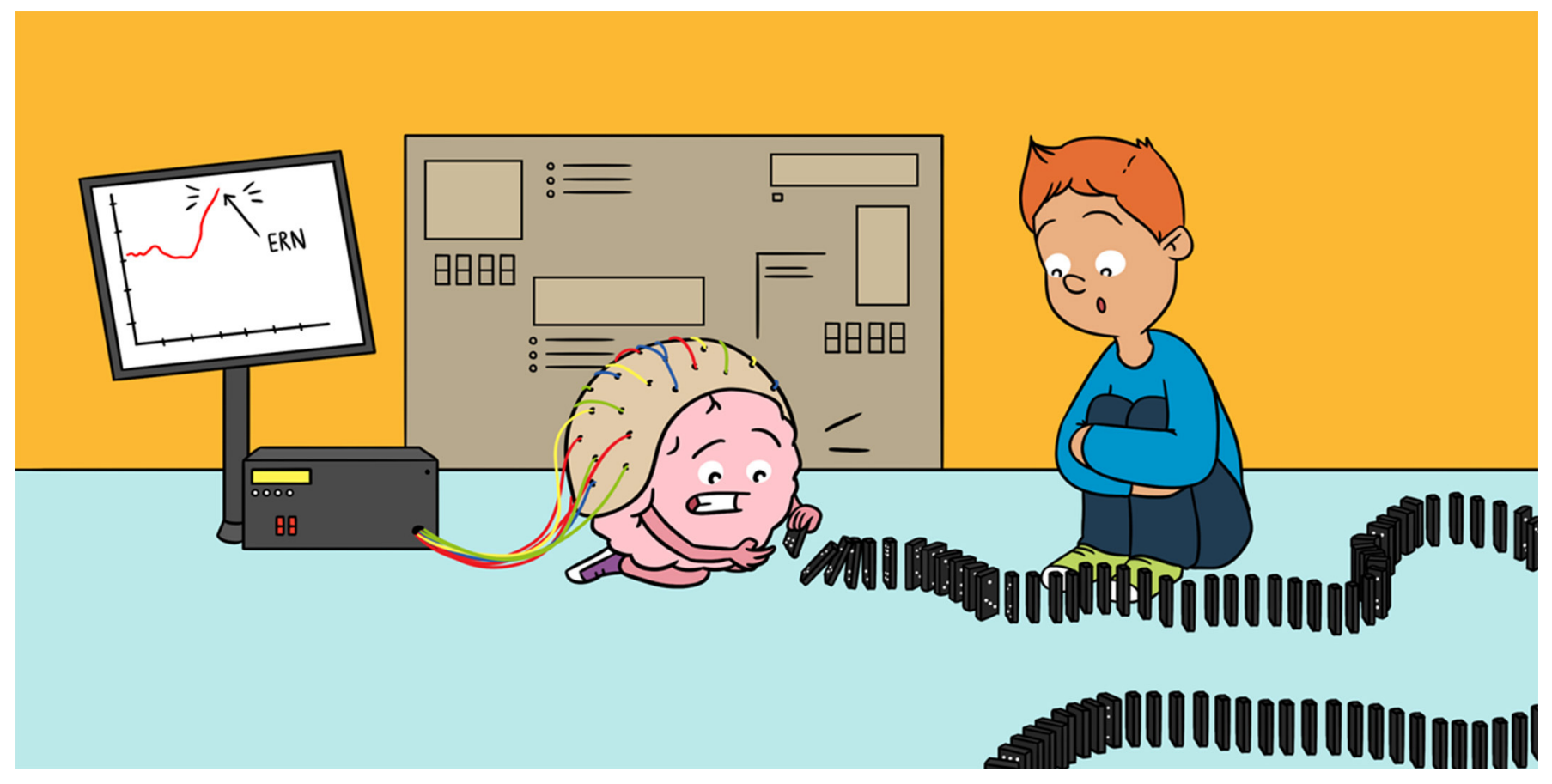

\title{
LEARNING FROM MISTAKES: HOW DOES THE BRAIN HANDLE ERRORS?
}

\author{
Knut Overbye ${ }^{1}$, Rune Bøen ${ }^{2}$, Rene J. Huster ${ }^{3}$ and Christian K. Tamnes ${ }^{2,4,5^{*}}$ \\ ${ }^{1}$ Center for Lifespan Changes in Brain and Cognition, Department of Psychology, University of Oslo, Oslo, Norway \\ 2PROMENTA Research Center, Department of Psychology, University of Oslo, Oslo, Norway \\ ${ }^{3}$ Multimodal Imaging and Cognitive Control Lab, Department of Psychology, University of Oslo, Oslo, Norway \\ ${ }^{4}$ NORMENT, Institute of Clinical Medicine, University of Oslo, Oslo, Norway \\ ${ }^{5}$ Department of Psychiatric Research, Diakonhjemmet Hospital, Oslo, Norway
}

YOUNG REVIEWERS:

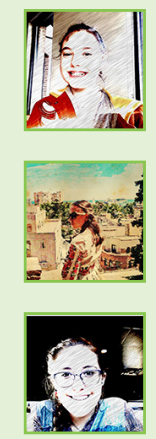

ASHLEY

AGE: 12

JULIA

AGE: 14

SAMANTHA

AGE: 15
We all make mistakes-and when we do, it is a great opportunity for the brain to adjust what it is doing and to learn. To study how the brain detects and deals with errors, researchers have used caps equipped with sensors that can measure brain activity. One thing researchers have found using this method is that the brain creates a specific kind of brain activity when a person makes a mistake. This activity, called the error-related negativity or ERN, happens almost at the same time that the error is made. It is as if the brain already knows we are making a mistake within fractions of a second, before we are even aware of it. Where in the brain does this ERN come from? How does it help us learn? And how does it change as we develop from children to adults? 


\section{MAKING MISTAKES}

Making a mistake feels bad. That sudden annoying jolt you feel when the dart misses the dartboard or the sinking feeling you get when you get an $\mathrm{F}$ on a test. These feelings can be annoying or painful, but they are part of what your brain does to make you succeed in the future.

Making a mistake could have meant injury or death for our distant ancestors who lived in the wild, hunting game and avoiding predators. The brains of our ancestors had to help them learn from their mistakes, so that the human race could survive. An important function of the brain is to try to predict the future. This includes how we can change our actions in the future, to avoid making the same mistakes. Understanding how the brain detects and copes with mistakes is therefore important for understanding how the brain works and how we learn.

We can think of a mistake like this: you start out with a goal you want to achieve. Perhaps you are playing soccer and you are about to make a free kick. Your goal is literally to score a goal. You assess the situation and choose a plan of action. Say the opposing team has set up a wall, so you decide to curve the ball around the players and into the goal. But you put too little spin on the ball, and it hits a goal post and deflects.

In this example, the mistake was caused by an incorrect prediction. You predicted that the way you kicked the ball would result in you scoring a goal but, to your surprise, it hit the goal post instead! In other words, what you thought would happen did not actually happen. Although you might be disappointed for not scoring a goal, this event tells you something very important. It tells you that your ideas about how the world works and how you can affect it are not completely correct. Now you know that, next time, you will need to kick the ball with more spin. Thanks to such learning experiences, you will fine-tune your kicking until you ultimately score.

\section{HOW DOES THE BRAIN DEAL WITH ERRORS?}

Brain cells communicate with each other using electricity. Some of this electrical activity travels away from the brain cells to the outside of the head. It passes through brain tissue, the skull, and your skin along the way. By using caps with special sensors called electrodes, we can record this activity; this method is called electroencephalography

ELECTRO

ENCEPHALOGRAPHY (EEG)

A method to record electrical activity of the brain.
(EEG). EEG allows us to study brain activity while people perform different tasks. The brain never stops working, even when you sleep, and thus constantly produces this electrical activity. By looking at patterns in these electrical "brain waves," it is possible to see a lot about what is going on in the brain. We can see if people are awake 
Figure 1

The error-related negativity (ERN) and the error positivity. A specific pattern of brain activity can be observed when we make an error. In the graph, the wavy line shows the brain activity over time. The vertical line represents the time at which the error was made. You can see that the ERN (blue), happens almost immediately after the error is made and is strongest at the top of the head, while the error positivity (red), comes a bit later.

\section{ERROR RELATED} NEGATIVITY (ERN)

Negatively charged electrical brain activity which happens very quickly after an error and which signals detection and processing of the error

\section{CINGULATE CORTEX}

A part of the brain deep inside in the middle of the brain.

\section{CINGULUM BUNDLE}

\section{A nerve tract}

containing a collection of fibers that connect many different parts of the brain.

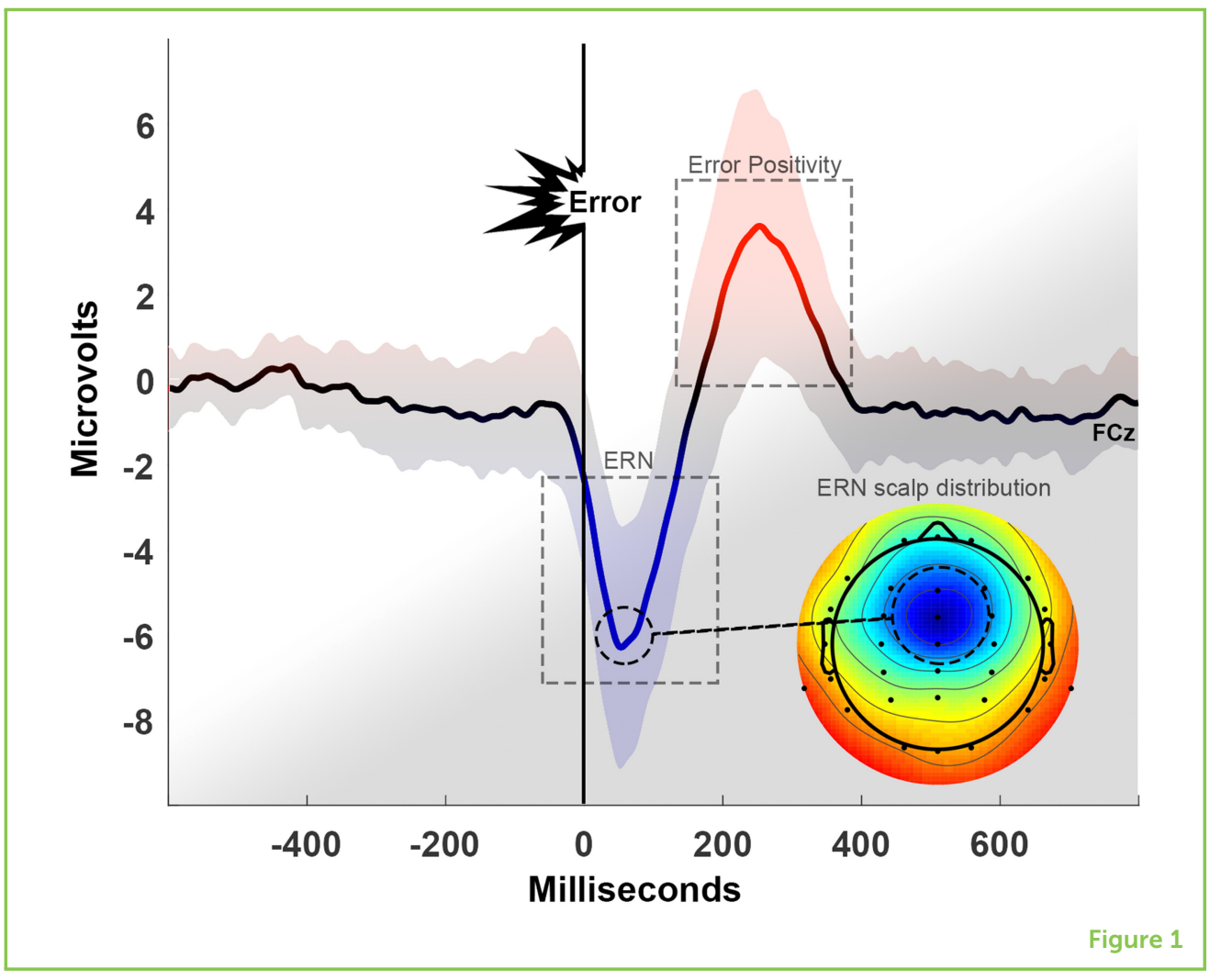

or sleeping, if they are relaxed or focused, or if they just made an error.

In the laboratory, we study brain activity related to errors by giving someone a very difficult task, in which he or she is bound to make a lot of errors. For example, the person might be asked to quickly press a certain key on a keyboard when a left or right arrow is shown at the center of the screen, but the arrow is surrounded by many distracting arrows pointing in the other direction. Whenever the person makes an error, a special pattern of brain activity shows up: a sharp, negative electrical activity that is strongest at the top of the head. Since this electrical activity is negatively charged and associated with making errors, it is called the error-related negativity, or ERN [1] (Figure 1).

The ERN is thought to come from a brain region deep inside the front part of the brain called the cingulate cortex [2] (Figure 2). The ERN is likely the result of the cingulate cortex detecting an error and sending an alert signal to other parts of the brain, through connections called the cingulum bundle, focusing the person's attention to decrease the likelihood of making new mistakes.

A curious thing about the ERN is how quickly it happens after you make an error. So quickly, in fact, that it happens before you are aware of your mistake. The ERN usually occurs no later than $100 \mathrm{~ms}(1 / 1,000$ of a second) after an error has been made. The ERN can even occur at 
Figure 2

The cingulate cortex and the cingulum bundle. Left: The cingulate cortex, shown in green, is a region deep inside in the middle of the brain, and is the source of the ERN. Right: The cingulum bundle, the fiber connections that lie underneath the cingulum cortex, connects different brain regions (made by Sila Genc).

\section{ERROR POSITIVITY}

(PE)

Positively charged electrical brain activity which happens from $200 \mathrm{~ms}$ after an error and is involved in our awareness of making the error.

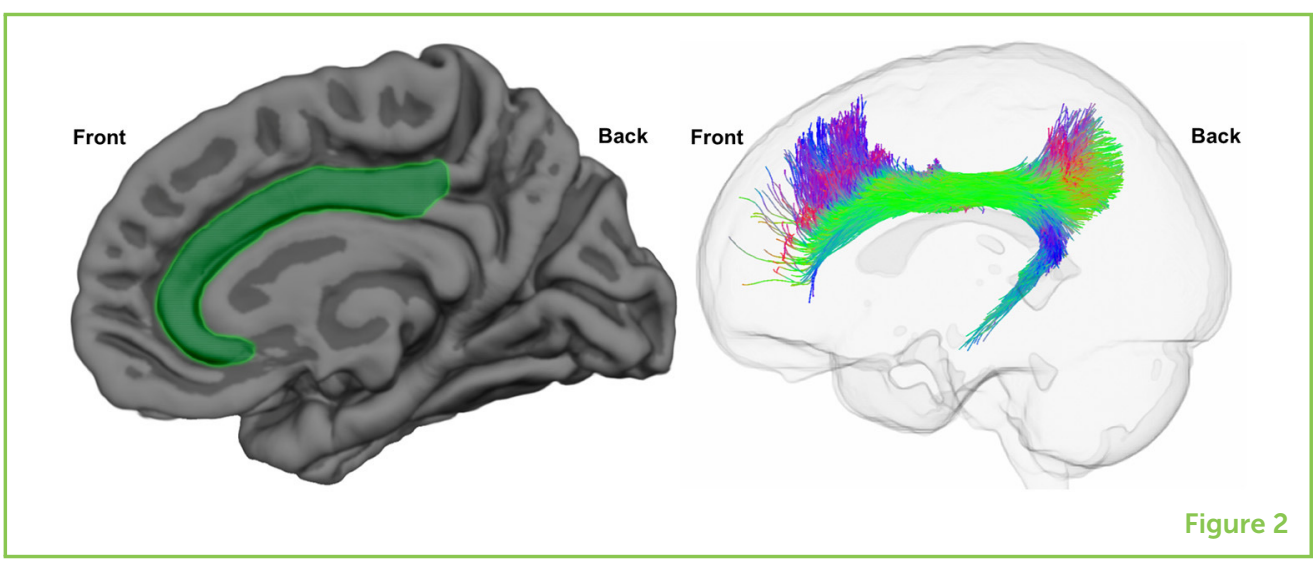

almost the exact same time as the error itself. In contrast, you will not have a feeling of making an error until at least 200 ms later. It is like your brain knows you have made a mistake before "you" do! And indeed, scientists think that this is exactly what happens. The cingulate cortex compares our actual actions to what we would like to do or should achieve, and the ERN then signals to our conscious self that the actual action and the outcome we expected do not match. The ERN thus brings this error or mismatch to our attention. The actual awareness of making an error happens at the same time as a later brain signal, called the error positivity, which is an electrical signal that scientists believe to be involved in our awareness of making an error.

\section{HOW DO ERRORS HELP US ADJUST OUR BEHAVIOR AND LEARN?}

Many scientific studies have found that, after making a mistake, we respond more slowly in the next round. This might be because the brain is trying to give itself more time, to avoid making the same mistake again. The stronger the ERN is after an error, the slower the response in the next round tends to be [3].

Some people have a larger ERN than others. Does this mean that these people are more sensitive to making errors and learn more from their mistakes? Some studies seem to support this idea. For instance, Hirsh and Inzlicht [4] found that a stronger ERN was associated with better school performance. In their study, the researchers measured the brain activity of university students and found that the students who had a larger ERN also tended to have better grades.

Having a strong ERN is not necessarily always a good thing, however. People who are more anxious tend to have stronger ERNs [5], and very strong brain responses to errors are associated with increased distractibility rather than improved focus. If the ERN shows the brain reacting and responding to errors, then a really strong ERN might be the brain overreacting, being more upset and alarmed by making a mistake than is necessary. 


\section{HOW DO ERROR SIGNALS CHANGE AS WE GROW UP?}

In childhood and adolescence, the body goes through many physical changes, but there are also many changes in how we think, feel, and behave, and in our motivations. These changes, along with the ever-greater responsibilities and expectations we face in life, require repeated trial-and-error in order for us to learn the social and academic skills we need to thrive as adults.

Studies show that the ERN changes with age, with adults and older teenagers having stronger ERN signals compared to children [3]. That the ERN increases in strength through childhood and adolescence is probably related to the way the brain develops. Different parts of the brain develop at different speeds. Some brain regions are fully mature by late childhood, while others continue to develop into adulthood [6]. The cingulate cortex, which produces the ERN, does not stop developing until the late 20s. In other words, a part of the brain that is important for learning from our mistakes takes a really long time to develop compared to many other parts of the brain.

\section{CONCLUSION}

Making mistakes can be annoying and frustrating at times. However, it is also very important for us to learn from our mistakes, so we can correct our responses and do things differently the next time we are in the same situation. The brain is very sensitive to mistakes and it produces a specific type of electrical activity when we make errors, called the ERN. This error signal: (1) occurs before we are aware of our mistake; (2) becomes more powerful as we get older; and (3) can predict how well we perform at school or university. There is still much we do not know about how the brain reacts to mistakes. Doing more research on the ERN might help us solve some of these mysteries.

\section{ACKNOWLEDGMENTS}

We would like to wholeheartedly thank those who assisted in the translation of the articles in this Collection to make them more accessible to kids outside English-speaking countries, and for the Jacobs Foundation for providing the funds necessary to translate the articles. For this article, we would especially like to thank Tieme Janssen for the Dutch translation. CT was supported by the Research Council of Norway (\#230345, \#288083, \#223273) and the South-Eastern Norway Regional Health Authority (\#2019069). 


\section{REFERENCES}

1. Tamnes, C. K., Walhovd, K. B., Torstveit, M., Sells, V. T., and Fjell, A. M. 2013. Performance monitoring in children and adolescents: a review of developmental changes in the error-related negativity and brain maturation. Dev. Cogn. Neurosci. 6:1-13. doi: 10.1016/j.dcn.2013.05.001

2. Cavanagh, J. F., and Frank, M. J. 2014. Frontal theta as a mechanism for cognitive control. Trends Cogn. Sci. 18:414-21. doi: 10.1016/j.tics.2014.04.012

3. Overbye, K., Walhovd, K. B., Paus, T., Fjell, A. M., Huster, R. J., and Tamnes, C. K. 2019. Error processing in the adolescent brain: Age-related differences in electrophysiology, behavioral adaptation, and brain morphology. Dev. Cogn. Neurosci. 38:100665. doi: 10.1016/j.den.2019.100665

4. Hirsh, J. B., and Inzlicht, M. 2010. Error-related negativity predicts academic performance. Psychophysiology 47:192-6. doi: 10.1111/j.1469-8986.2009.00877.x

5. Hajcak, G. 2012. What we've learned from mistakes: insights from error-related brain activity. Curr. Direct. Psychol. Sci. 21:101-6. doi: 10.1177/0963721412436809

6. Amlien, I. K., Fjell, A. M., Tamnes, C. K., Grydeland, H., Krogsrud, S. K., Chaplin, T. A., et al. 2016. Organizing principles of human cortical development-thickness and area from 4 to 30 years: insights from comparative primate neuroanatomy. Cereb. Cortex 26:257-67. doi: 10.1093/cercor/bhu214

SUBMITTED: 01 October 2019; ACCEPTED: 18 May 2020; PUBLISHED ONLINE: 16 June 2020.

EDITED BY: Nienke Van Atteveldt, Vrije Universiteit Amsterdam, Netherlands

CITATION: Overbye K, Bøen R, Huster RJ and Tamnes CK (2020) Learning From Mistakes: How Does the Brain Handle Errors? Front. Young Minds 8:80. doi: 10. 3389/frym.2020.00080

CONFLICT OF INTEREST: The authors declare that the research was conducted in the absence of any commercial or financial relationships that could be construed as a potential conflict of interest.

COPYRIGHT @ 2020 Overbye, Bøen, Huster and Tamnes. This is an open-access article distributed under the terms of the Creative Commons Attribution License (CC BY). The use, distribution or reproduction in other forums is permitted, provided the original author(s) and the copyright owner(s) are credited and that the original publication in this journal is cited, in accordance with accepted academic practice. No use, distribution or reproduction is permitted which does not comply with these terms.

\section{YOUNG REVIEWERS}

\section{ASHLEY, AGE: 12}

Hi I am Ashley!! I like to dance flamenco everyday because it is fun and is a great physical activity. Flamenco and acting class are my favorite classes this year. I go to 

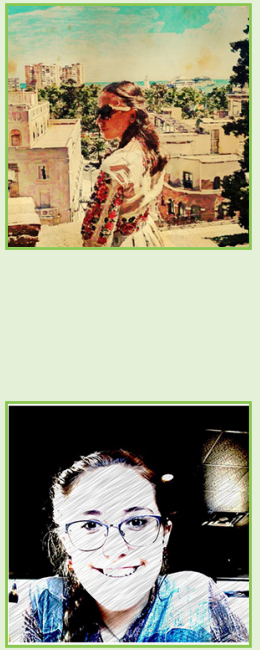

a school that focuses not just on normal classes, but on performing arts as well. In my spare time I like making jokes and playing card games with my family.

\section{JULIA, AGE: 14}

My name is Julia and I am a ninth grader from Berlin. I am a student who is very interested in math, chemistry, and sciences, especially neuro- and space sciences or quantum mechanics, but I enjoy learning languages too. At home I am talking with my parents in Ukrainian because originally we come from Ukraine and in addition I am studying German, English, and French at school. In my free time I really like playing the piano, dancing, and reading books.

\section{SAMANTHA, AGE: 15}

Hi my name is Samantha! I like to read and write, and I am working on writing a long story right now. My favorite classes are Chemistry and English. In my free time I enjoy contemplating the mysteries of the universe, staring off into space, and writing stories.

\section{AUTHORS}
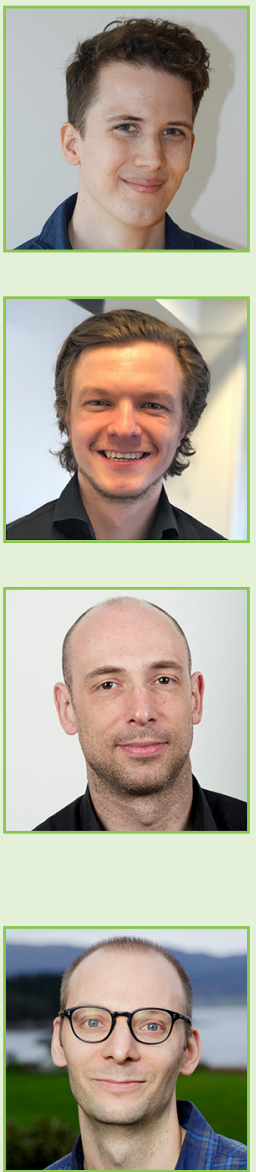

\section{KNUT OVERBYE}

Knut is a psychologist and cognitive neuroscientist. He has studied how adolescent brains react to errors and surprises. He is currently studying how the brain changes physically when we practice something for a long time. Both at work and at home, Knut enjoys programming and finding new uses for virtual reality.

\section{RUNE BØEN}

Rune is a research assistant and helps other researchers to perform experiments. $\mathrm{He}$ is interested in the brain and how it works, and wants to become a cognitive neuroscientist in the future. He enjoys science and learning new things. When he is off work, he likes to read books, listen to podcasts, and watch soccer games.

\section{RENE J. HUSTER}

René is a cognitive neuroscientist who studies how the brain helps us to adapt to changes in the environment, and how we can function under challenging conditions, for example, how can you resist eating a cookie now, when you might get three more if you wait another $30 \mathrm{~min}$ ? When he is not working, he likes to practice Jiu Jitsu or the bass guitar.

\section{CHRISTIAN K. TAMNES}

Christian is a psychologist and a developmental cognitive neuroscientist. He studies how the brain develops through childhood and adolescence. He is also interested in how the development of the brain makes us who we are. In his research, he tries to figure out if the shape and function of the developing brain can tell us something about why some people are very outgoing or smart, or even why some people get mentally ill. In his free time, he mostly hangs out with his two kids. *c.k.tamnes@apsykologi.uio.no 